\title{
O caudilho da sociologia mexicana Pablo González Casanova e A democracia no México
}

\author{
Luiz Carlos Jackson e Alejandro Blanco
}

Uma visada sobre a trajetória e a obra de Pablo González Casanova, liderança principal no processo de institucionalização da sociologia mexicana na década de 1960, permite inquirir seu padrão específico por meio da comparação com os casos brasileiro e argentino. Nos três prevaleceram iniciativas nacionais durante a fase fundacional (1930-1970) de institucionalização dessa disciplina na América Latina ${ }^{1}$ e neles se constituíram, se bem que com alcances distintos, experiências convencionalmente designadas como "escolas" sociológicas (Jackson e Blanco, 2014).

Nos três países, tais processos tiveram como condicionantes gerais mudanças profundas nas estruturas sociais, nos sistemas políticos e nos mercados de bens culturais nas primeiras décadas do século Xx e, como suportes diretos, inovações nas organizações de ensino superior, introduzidas principalmente nas instituições que, em cada um desses países, se constituíram, ao longo do século Xx, nas universidades mais importantes da América Latina: a Universidade Nacional Autônoma do México (Unam), a Universidade de Buenos Aires (UBA) e a Universidade de São Paulo

1. A esse respeito, é possível diferenciar tipicamente dois vetores de institucionalização das ciências sociais na América Latina: as iniciativas nacionais e as transnacionais. Embora nenhuma experiência nacional possa ser compreendida unicamente a partir de um desses dois vetores, elas se diferenciam entre as que se apoiaram prioritariamente em um ou outro e em função do tipo de composição deles derivada. No caso chileno, em oposição aos casos examinados neste artigo, predominaram as iniciativas transnacionais. 
(USP). As dimensões principais a serem mobilizadas como parâmetros de comparação referem-se às transformações sociais e às dinâmicas específicas de urbanização na Cidade do México, em Buenos Aires e São Paulo, às relações vigentes em cada caso entre intelectuais e Estado (dimensão privilegiada neste texto), às modalidades de organização dos sistemas acadêmicos, aos padrões de recrutamento social dos cientistas sociais, às obras produzidas (volume, temas, estilos de trabalho, perspectivas de análise).

Nos dois próximos itens reconstituiremos a trajetória social e intelectual de Pablo González Casanova no contexto das décadas iniciais de institucionalização da sociologia mexicana. No último item ensaiaremos uma comparação entre essa experiência e as da Argentina e do Brasil, centradas nas lideranças exercidas por Gino Germani e Florestan Fernandes, respectivamente.

A designação como Universidade Nacional Autônoma do México ocorreu no ano de 1929, em decorrência das tensões que opuseram elites políticas e intelectuais/científicas desde a irrupção da Revolução Mexicana (1910). A universidade havia sido criada nos últimos momentos do regime de Porfirio Díaz (1877-1911), por iniciativa de seu ministro de educação e principal porta-voz intelectual, Justo Sierra, o que explica o distanciamento inicial da comunidade científica em relação ao processo revolucionário. A polarização entre os que entendiam a universidade como instituição subordinada ao Estado e os que reivindicavam sua autonomia permaneceria como fundamento dos conflitos que se prolongariam até pelo menos meados da década de 1940 (Lempérière, 1992; Garciadiego, 1996).

$\mathrm{Na}$ década de 1920, sob a liderança do escritor José Vasconcelos, instado pelo então presidente Álvaro Obregón, à frente da Secretaria de Educação Pública, a Universidade Nacional começaria a ser assimilada aos propósitos do Estado pós-revolucionário, o que nas palavras de Vasconcelos em seu discurso de posse como reitor da Universidade (antes de assumir a Secretaria) em 1920 ficava muito claro:

Eu sou, neste momento, mais que um novo reitor que sucede os anteriores, um delegado da Revolução que não veio procurar refúgio para meditar no ambiente tranquilo das salas de aula, e sim para convidá-los a que saiam comigo à luta, que compartam conosco as responsabilidades e os esforços. Neste momento eu não venho trabalhar pela universidade, mas pedir à universidade que trabalhe pelo povo (Vasconcelos, 1920, citado por Monsiváis, 1986, p. 1416).

$\mathrm{O}$ arrefecimento dessa disputa (condicionada em boa medida pela instabilidade política pós-revolucionária) no interior da universidade se daria em função da 
institucionalização do sistema político mexicano por meio da criação do Partido Nacional Revolucionário (PNR) no final de 1928, da primeira proclamação da autonomia universitária (1929) e do posterior esgotamento do ciclo dos governos militares ${ }^{2}$, demarcado pela eleição de Miguel Alemán em 1946, presidente civil e advogado egresso da Escola Nacional de Jurisprudência da Unam. Desde então prevaleceria entre Estado e intelectuais acadêmicos uma relação de aproximação, se não isenta de conflitos, pautada por uma maior convergência de interesses. Esta seria favorecida, ainda, pelo longo ciclo de expansão econômica alicerçado na nacionalização da produção de petróleo durante a presidência de Lázaro Cárdenas no final da década de 1930, que englobou o período inicial de institucionalização universitária no país e que constituiu o lastro financeiro do investimento estatal no sistema de educação superior.

O processo de alinhamento da universidade ao Estado pós-revolucionário deve ser relacionado, também, com o conjunto de iniciativas estatais empreendidas desde a década de 1920 e, sobretudo, nas duas décadas seguintes, quando foram criadas novas instituições de ensino, pesquisa e difusão cultural no interior da universidade e fora dela, que abrigaram as elites intelectuais e acadêmicas: Escola Nacional de Economia (1934), Instituto Nacional Politécnico (1937), Escola Nacional de Antropologia e História (1938), Colégio do México (1939), Instituto Indigenista Interamericano (1940), Instituto Nacional de Belas Artes (1946), Instituto Nacional Indigenista (1948), editora Fondo de Cultura Económica (1934), as academias Seminário de Cultura Mexicana (1942) e Colégio Nacional (1943), além dos prêmios nacionais em Artes, Ciências e Letras (1945). A inauguração da cidade universitária, em 1951, coroaria esse processo de investimentos públicos que viriam a constituir a base concreta do sistema cultural e universitário, relativamente integrado em função de sua dependência (em graus distintos) ao Estado. Devemos notar que o Estado mexicano centralizou mais que na Argentina e no Brasil a promoção da vida cultural, compensando a extrema debilidade de seu mercado privado de bens culturais, que já era forte na Argentina e, ainda que em menor medida, também no Brasil, nas décadas de 1930 e 1940.

Diversos trabalhos de Roderic Camp (1981, 1983 e 1988) demonstraram a vinculação estreita entre elites políticas e elites intelectuais no México pós-revolucionário em função de condicionantes como a origem urbana compartilhada e a socialização na Cidade do México; a experiência educacional comum, transcorrida quase exclusivamente na Escola Nacional Preparatória e na Unam; a incorporação

2. Durante as três primeiras décadas após o início da revolução (1910), quase todos os presidentes haviam sido líderes militares destacados durante o processo revolucionário. 
e o desempenho prolongado dos intelectuais nos vários níveis da burocracia e da estrutura política do Estado.

A relação mais direta entre elites intelectuais e políticas envolveria os formados da Escola Nacional de Jurisprudência e da Escola Nacional de Economia, muitos deles recrutados para altos cargos políticos no Estado. Camp demonstra que as relações de amizade urdidas na preparatória e na universidade foram decisivas para possibilitar o ingresso no sistema político. Os escritores e $\operatorname{artistas}^{3}$, mais ou menos comprometidos com o projeto da revolução, seriam, de modo geral, direcionados ao trabalho diplomático e às várias instâncias da gestão cultural (Garciadiego, 2010). Os antropólogos, os sociólogos e os historiadores, alocados na universidade e no Colégio do México, também ocuparam importantes cargos políticos e técnicos no Estado (Lempérière, 1992; Palacios, 2010; Kourí, 2010).

No âmbito específico das ciências humanas e sociais (objeto deste texto), cuja institucionalização se iniciou em torno da década de 1930 - precedida por iniciativas precursoras voltadas às pesquisas arqueológicas, então de grande interesse político para a construção da identidade nacional ainda na década de 1910 -, tais produtores culturais enfrentaram condições ambíguas à autonomização de suas atividades, em função dos constrangimentos políticos a que estavam submetidos, derivados da vinculação dupla com a instituição universitária e com o Estado. A antropologia e a história foram as disciplinas que receberam impulso inicial mais forte, sobretudo, pelo papel que podiam cumprir para o Estado de recuperar ou construir versões acerca da formação histórica e social da nação afinadas com o processo revolucionário, e isso implicou um processo de modernização disciplinar anterior, que teve em Manuel Gamio (1883-1960), para a antropologia, e Daniel Cosío Villegas (1898-1976), para a história ${ }^{4}$, suas lideranças principais.

O ensino de sociologia no México até o começo da década de 1950 tinha lugar nos cursos de direito, sobretudo. A pesquisa seria impulsionada no Instituto de Pesquisas Sociais (IIs) da Unam (1930), a partir de 1939, quando Lucio Mendieta y Núñez (1895-1988), que viria a ser a liderança principal nas décadas iniciais de institucionalização da sociologia no México, assumiu sua direção, criando a Revista Mexicana de Sociologia, principal veículo de divulgação das pesquisas realizadas no país até pelo menos a década de $1970^{5}$ e uma das mais importantes revistas de

3. Na década de 1920, os pintores muralistas, sobretudo José Clemente Orozco, Diego Rivera e David Siqueiros, patrocinados pelo Estado, desempenharam um papel fundamental na propaganda ideológica revolucionária e se projetaram como os grandes artistas mexicanos da metade do século xx (Hennessy, 1991).

4. Apesar do distanciamento progressivo de Cosio Villegas em relação ao projeto ideológico da Revolução (Cosio Villegas, 1976; Krauze, 1980).

5. Trata-se da revista mais antiga de sociologia na América Latina, em edição contínua até o presente, favo- 
ciências sociais na América Latina. Tanto o instituto como a revista resultaram, entretanto, de iniciativas nascidas no seio do Estado, comprometidas com a visão de que a sociologia deveria servir como um instrumento para as políticas públicas, reivindicada explicitamente por Mendieta y Núñez num contexto em que, como vimos, a controvérsia sobre a autonomia universitária havia se resolvido na prática a favor de um compromisso entre o Estado e a universidade.

Nascido na cidade de Oaxaca, a origem social modesta de Mendieta y Núñez ${ }^{6}$ sugere que a revolução abriu brechas de ascensão social, mesmo que restritas, para os grupos desfavorecidos por meio do acesso à educação pública ${ }^{7}$ e explica em boa medida sua adesão ao Partido Revolucionário Institucional (PRI), comprovada por sua longa carreira no serviço público, iniciada logo após sua formatura em direito $(1920)^{8}$. Sua aproximação ao antropólogo Manuel Gamio, ainda quando cursava a graduação, e o apoio que lhe proporcionou desde então foram decisivos para que concluísse o curso e para sua posterior inserção acadêmica e profissional ${ }^{9}$, marcada

recida pelo persistente apoio estatal, ancorado no padrão de institucionalização acadêmica fortemente lastreado no Estado. Isso se comprova com outras instituições longevas e de enorme peso na região, como as revistas Cuadernos Americanos (editada desde 1942) e Trimestre Económico (editada desde 1934), e a editora Fondo de Cultura Económica (criada em 1934).

6. Cabe citar: Em um "país em que nove de cada dez famílias pertenciam ao setor mais pobre da população, apenas um de cada dez integrantes desta geração [de 1915] provinha delas. A essa décima porção dos mexicanos pertenceu Mendieta” (Serrano, 2004, p. 42). Uma análise sobre a origem social e a primeira parte da trajetória intelectual de Mendieta encontra-se em Reséndiz Saucedo (2016).

7. A revolução implicou uma profunda transformação da estrutura social no México, sobretudo em função da expropriação da antiga elite proprietária de terras (Iturriaga, 1951), e o incremento da mobilidade, vertical e horizontal. Assim, as antigas elites sociais e políticas tiveram que inventar estratégias de recuperação social, as classes populares tiveram mais oportunidades de ascender e houve crescimento das classes médias urbanas. Sem negligenciar os efeitos da modernização (crescimento econômico, industrialização e diferenciação social) sobre o sistema ocupacional, esse processo de reconfiguração da sociedade teve como suporte decisivo a expansão do aparato político e burocrático do Estado, do sistema educacional e das instituições culturais. No bojo desse processo, novas possibilidades de profissionalização foram geradas.

8. Desde 1921, Mendieta y Núñez ocupou diversos cargos, tanto no âmbito do Estado, como do partido: em 1921, chefe do Departamento de População Contemporânea da Direção de Antropologia da Secretaria de Agricultura e Fomento; em 1934, chefe do Instituto de Investigações Sociais desse organismo; em 1935, organizador e diretor do Instituto de Estudos Políticos, Econômicos e Sociais do Partido Nacional Revolucionário e fundador da revista Politica Social; em 1936, conselheiro do Departamento de Assuntos Indígenas; em 1946, oficial maior do Departamento Agrário.

9. De acordo com seu depoimento: "Não poderei nunca esquecer que quando, em tempos de juventude, se abatia sobre mim infeliz destino, que me obrigava a abandonar os estudos profissionais apenas iniciados, conheci graças a Carlos Noriega Hope, dileto companheiro de escola, Don Manuel Gamio, que tinha então a seu cargo a recém-criada Direção de Antropologia, vinculada à Secretaria de Agricultura e Fomento. Apesar das limitações de orçamento, ele me ofereceu um emprego de escrevente, o mais modesto na escala burocrática, mas me autorizou a continuar o curso escolhido e, quando necessário, a não comparecer ao escritório, a fim de me preparar para os exames de fim de curso. Não poderia ter sonhado com uma acolhida mais generosa" (Lucio Mendieta e Núñez, 1979, p. 56). 
pela atuação combinada nos meios político e acadêmico, o que seria um padrão para as primeiras gerações de cientistas sociais mexicanos (quase todos formados em direito). Dessa posição, reivindicou, sobretudo, a sociologia como disciplina aplicada, diretamente interessada e empenhada na solução dos problemas sociais do país, em consonância com as demandas políticas do Estado mexicano pós-revolucionário, embora a amplitude temática de sua obra ${ }^{10}$ sinalize o esforço de fortalecer a disciplina em outras bases e não, exclusivamente, como instrumento a serviço do Estado. De qualquer modo, Lucio Mendieta y Núñez concebeu e organizou o quadro institucional da sociologia em seu país, estabeleceu um padrão respeitável de produção sociológica, meios para a divulgação desse tipo de conhecimento e articulações na cena internacional e na América Latina, em especial com sociólogos argentinos e brasileiros.

O processo de institucionalização das ciências sociais no México foi beneficiado pela presença de intelectuais espanhóis (vários autores, 1982 e 1999; Zabludovski, 2002) que haviam emigrado depois da derrota dos republicanos na Guerra Civil (1936-1939). O presidente Lázaro Cárdenas adotou uma política explícita de acolhimento, principalmente por meio da criação da Casa de Espanha em 1938, convertida em 1940 no Colégio do México - instituição central para o desenvolvimento da pesquisa científica especialmente nas áreas de história e filologia -, presidido até 1959 pelo escritor Alfonso Reyes. Fizeram parte dessa emigração intelectual, por exemplo, os filósofos José Gaos, Joaquín Xirau, Eugenio Ímaz e Eduardo Nicole, os historiadores José Miranda e Ramón Iglesias, além do sociólogo José Medina Echavarría, que iniciou na América Latina um movimento de renovação intelectual da sociologia, visando a seu estabelecimento como ciência empírica que, se não prosperou de imediato no México, teve continuidade na Argentina, no Brasil e no Chile.

Medina Echavarría ${ }^{11}$ (1903-1977) havia estudado direito e filosofia e se familiarizara com a sociologia alemã durante duas estadias prolongadas nesse país no começo da década de 1930, ainda no contexto da República de Weimar. Detinha uma bagagem sociológica considerável quando chegou ao México, disposto, como vimos, a investir na renovação científica dessa disciplina, projeto que ficaria grafado nas páginas de Sociologia, teoria e técnica (1941). Em seguida à sua chegada, assumiu cursos de sociologia na Escola Nacional de Jurisprudência e na Escola Nacional de Economia da Unam (Gurrieri, 1980; Lira, 1986/1989), mas o fato mais importante para sua afirmação nesse momento foi sua atuação como diretor da coleção de so-

10. Explorou temas como questão indígena e agrária, estratificação social, burocracia, revolução, universidade, arte, partidos políticos. Para uma visão de conjunto de sua obra, ver Serrano (2004).

11. Sobre a biografia intelectual de Medina Echavarría, ver Martín (2012) e Moya (2013). 
ciologia na editora Fondo de Cultura Económica, que teve enorme importância em toda a América Latina. Sua tradução de Economia e sociedade foi decisiva à recepção de Max Weber na região, o que também ocorreu com a obra de Karl Mannheim (Blanco, 2004/2009; Morcillo, 2008).

O sociólogo enfrentou forte resistência, em parte por ser estrangeiro ${ }^{12}$, em parte em função do estado incipiente do desenvolvimento da sociologia no México. Em Sociologia, teoria e técnica, não obstante, ele chamou atenção para a necessidade de definir o estatuto científico da disciplina, tomando como referência o exemplo norte-americano. Defendeu uma espécie de síntese entre as orientações europeia e norte-americana, visando a um equilíbrio entre teoria e pesquisa empírica. Em 1943 criou com Daniel Cosío Villegas o Centro de Estudos Sociais (CES) no Colégio do México. Apesar do caráter renovador do projeto que animava o CES, a experiência fracassou após três anos de funcionamento, possivelmente em função do descompasso entre as expectativas de Medina Echavarría e as condições concretas que enfrentou, encarnadas nas divergências com Cosío Villegas, que imaginava um centro orientado à preparação de quadros para o governo, enquanto o primeiro tinha em mente um projeto prioritariamente científico. A transmigração do sociólogo espanhol em 1946 (ele foi inicialmente a Porto Rico e depois ao Chile) sugere que ele não encontrou no México condições adequadas ao desenvolvimento de seu projeto. Posteriormente, diante das circunstâncias com as quais se deparou no Chile, ele se incorporou à Comissão Econômica para a América Latina e Caribe - CEPAL (criada em 1947) no ano de 1952, instituição na qual exerceria um papel central, e assumiu em 1958 a direção da Escola Latino-americana de Sociologia da Faculdade Latino-americana de Ciências Sociais - Flacso (Blanco, 2010).

Em 1951 foi criada na Unam a Escola Nacional de Ciências Políticas e Sociais (ENCPys), que teve Lucio Mendieta y Núñez como mentor principal, embora fosse derrotado em sua aspiração de dirigir a nova escola (Olvera, 2001; Colmenero, 2003). Ela oferecia quatro cursos - Ciências Diplomáticas, Periodismo, Ciências Sociais e Ciência Política -, a partir de uma formação básica compartilhada. Em pouco tempo, a escola prosperou, atraindo um número cada vez maior de alunos. $\mathrm{O}$ contingente inicial de 141 inscritos cresceu a uma taxa média de 44\% até 1964, mas o curso de ciências sociais foi inicialmente o menos procurado. Sua principal dificuldade foi formar um quadro docente especializado, e isso se refletiu na orientação ainda caudatária do direito, formação de origem da maioria dos primeiros professores da escola. Em 1955, a escola ganharia força com o lançamento da Revista Mexicana

12. Um dado curioso de sua biografia é o fato de sua mãe, María de la Luz Echavarría y Cárdenas, ter nascido em Cuba, o que deve ser levado em conta para se entender o interesse do sociólogo pela América Latina. 
de Ciencias Politicas y Sociales e, a partir de 1957, sob a direção de Pablo González Casanova, uma orientação científica mais pronunciada.

A origem social de Pablo González Casanova (1922) contrasta sensivelmente com as do ítalo-argentino Gino Germani e do brasileiro Florestan Fernandes, um, imigrante, outro, filho de imigrante, ambos desprovidos de capital social e cultural herdado (Miceli, 2012; Jackson e Blanco, 2014). Germani (1911-1979), filho único de um alfaiate e velho militante socialista e de uma descendente de camponeses católicos, foi criado em um bairro de classe média baixa em Roma (Germani, 2004). A mãe de Florestan (1920-1995) era uma imigrante portuguesa e trabalhava como empregada doméstica na cidade de São Paulo (Arruda, 1995; Garcia, 2002). O nome de seu pai não constava em sua certidão de nascimento.

Pablo González Casanova descende de uma família tradicional em declínio. Oriundo, pelos lados paterno e materno, de grandes proprietários de terra do sul do México, na Península de Yucatan (Kahl, 1986), nasceu em Toluca no ano de 1922. Seu pai (1889-1936), de mesmo nome, fora enviado pela família a Alemanha com o objetivo de estudar química, visando a obter conhecimento técnico sobre agropecuária, mas se desviou desse destino ao seguir estudos em filologia. Permaneceu na Europa por nove anos, tendo vivido também na França, na Suíça, na Itália e em Portugal. Ao regressar ao México, três anos depois do início da revolução, em 1913, dedicou-se à atividade jornalística e ingressou na Unam como professor. Participou da importante pesquisa coordenada por Manuel Gamio, que originou o livro clássico da antropologia mexicana La población del valle de Teotibuacan, estudando o idioma náhuat ${ }^{13}$. Esse trabalho com Gamio relaciona-se, provavelmente, com a amizade travada naquele momento com Mendieta y Núñez. Entre 1932 e 1933, González Casanova pai trabalhou com o educador Moisés Sáenz na Estação Experimental de Incorporação do Índio, em Michoacán. Colaborou com Mariano Silva y Aceves, um dos fundadores do Ateneu da Juventude (1909) e reitor interino da Unam em 1921, na criação do Instituto Mexicano de Pesquisas Linguísticas da Unam. Atuou, também, como jornalista (no jornal El Universal dirigiu um suplemento cultural) e foi eleito para a Academia Mexicana da Língua.

Enfim, apesar de sua morte precoce (em 1936, quando tinha 46 anos), González Casanova pai participou de algumas das principais iniciativas culturais e universitá-

13. Pablo González Casanova foi, também, secretário de redação da revista Ethnos, fundada por Gamio em 1920, na qual colaborou também Lucio Mendieta y Nuñez (Olvera, 2016). 
rias (ele apoiou Manuel Gómez Morin em sua militância como reitor em defesa da autonomia universitária) durante as décadas de 1920 e 1930, e as relações urdidas com personagens-chaves do mundo intelectual de então pavimentariam as carreiras intelectuais posteriores de seus três filhos homens ${ }^{14}$. Para o pai, a carreira acadêmica já fora uma estratégia de recuperação social, uma vez que sua família havia sido, possivelmente, afetada pela revolução. Os filhos seguiram o mesmo caminho e tiveram a seu favor o capital social e cultural acumulado pelo pai.

Não seria possível entender a trajetória de Pablo González Casanova, no entanto, sem levar em conta as adversidades enfrentadas pelo grupo familiar, atingido pelo súbito falecimento do pai. Sua mãe, Concepción del Valle Romo, mobilizou os recursos, tanto materiais como sociais, de que dispunha (Manuel Gómez Morin lhe deu apoio e conseguiu um primeiro emprego para o futuro sociólogo), para garantir uma educação elevada para seus filhos ${ }^{15}$. O casamento de Pablo González Casanova com Natacha Henríquez Lombardo é, também, fundamental para avaliarmos o capital social de que dispunha no início de sua carreira. Ela era filha do reconhecido crítico dominicano Pedro Henríquez Ureña, a quem González Casanova pai conhecia ${ }^{16}$, e de Isabel Lombardo Toledano, irmã do "caudilho cultural" ${ }^{17}$ Vicente

14. Henrique González Casanova (1924-2004) estudou na Escola Nacional de Jurisprudencia da Unam, no Colégio do México e na Escola Nacional de Antropologia. Manuel González Casanova (19341912) realizou toda a sua formação na Faculdade de Filosofía e Letras da Unam, onde se graduou em letras e arte dramática, fez o mestrado em arte dramática e o doutorado em letras. Ambos atuaram profissionalmente no âmbito universitário e cultural, liderando importantes iniciativas culturais. Assim, por exemplo, o primeiro fundou e dirigiu, entre 1955 e 1961, a Direção Geral de Publicações da Unam, a primeira editora universitária do país; o segundo fundou a Filmoteca da Universidade Nacional Autônoma do México, em 1960, e o Centro Universitario de Estudos Cinematográficos (CUEC), em 1963.

15. "Nessa época me tornei mais estudioso. Minha mãe realizou um trabalho que cada vez me surpreende mais. Ela havia estudado em uma escola de freiras e sabia muito o francês, idioma em que conversava com meu pai cada vez que queriam que não nos inteirássemos do que estavam dizendo. Mulher muito inteligente, às vezes declarava sua ignorância e cultivava a memória de meu pai com a intenção de que o emulássemos até onde fosse possível. Mas não era tão ignorante como dizia, nem suas dúvidas sobre nós faziam que acreditássemos que era impossível ser como nosso pai. Ademais, minha mãe nos ensinou a ser mais organizados do que ele, por exemplo, que não guardássemos nossos livros de modo desorganizado como meu pai, o que tantos problemas havia causado para seu trabalho intelectual. Nos ensinou a ser pontuais numa época em que a pontualidade não era tão importante e contratou uma professora de inglês e outra de francês. Também nos ensinou a ajudá-la nas tarefas de casa, arrumávamos nossas camas e fazíamos outras coisas que nos tiraram um pouco a ideia de que esses não eram trabalhos de homens" (González Casanova, 1995).

16. Pablo González Casanova pai lecionou na Escola de Verão para Estrangeiros da Unam, coordenada por Pedro Henriquez Ureña, no começo dos anos de 1920 (Roggiano, 1989, p. 209).

17. De acordo com a expressão de Enrique Krauze em Caudillos culturales en la Revolución Mexicana (1976), que assim denominou os membros da geração de 1915 e o grupo dos "sete sábios" - Antonio Castro Leal, Alberto Vásquez de Mercado, Vicente Lombardo Toledano, Manuel Gómez Morin, Teó- 
Lombardo Toledano. Era filha e sobrinha, portanto, de dois dos personagens mais importantes e influentes da elite intelectual e política mexicana da primeira metade do século $\mathrm{xx}^{18}$.

Pablo González Casanova estudou e se formou em contabilidade (o que o familiarizaria com métodos quantitativos de análise, mobilizados posteriormente em $A$ democracia no México) antes de ingressar no curso de direto da Escola Nacional de Jurisprudência, que deixou inconcluso para estudar história no Colégio do México, onde fez o mestrado e pôde absorver o hábito de trabalho sistemático dos professores espanhóis ${ }^{19}$. Quase simultaneamente, desde 1943 foi recrutado por Mendieta y Núñez, “amigo de meu pai” (González Casanova, 1995, p. 12), para trabalhar como pesquisador no Instituto de Investigações Sociais da Unam (IIS). Desde o princípio de sua carreira, portanto, esteve dividido entre a história e a sociologia, mais empenhado na primeira, até realizar o doutorado na França, e na segunda, depois disso. Quem o estimulou, inicialmente, a estudar na França (ele recebeu uma bolsa do governo francês) foi Mendieta y Nuñez, mas ele obteve apoios institucionais e financeiros, tanto do IIs, como do Colégio do México. Seu primeiro livro, El misoneísmo y la modernidad cristiana en el siglo XVIII (sua dissertação de mestrado, defendida em 1947), foi publicado pela editora do Colégio do México em 1948 e reflete diretamente a forte tradição em história das ideias ${ }^{20}$ aportada no México pelos espanhóis. Em 1950 defendeu seu doutorado na França, sob orientação de Fernand Braudel $^{21}$, com a tese Introductión à la sociologie de la connaissance de l'Amérique

filo Olea y Leyva, Alfonso Caso e Jesús Moreno Baca -, sobretudo a Manuel Gómez Morin e Vicente Lombardo Toledano.

18. Além da evidente ampliação do círculo de relações propiciado pelo casamento, Natacha González Casanova del Valle (seu nome após o casamento) teria propiciado a seu marido uma aproximação ao universo da "alta" cultura, por meio das relações com a elite literária mexicana, conforme o depoimento do autor, avaliando sua estadia em Paris, onde realizou o doutorado: "Eu havia me casado e minha mulher me pressionou para que fosse mais culto ou menos ignorante dos grandes romancistas da França, Inglaterra, Alemanha, Rússia e Itália. [...] Com ela também aprendi a me interessar pelas conversações das pessoas cultas, com memória e senso de humor, e boutades generosas ou provas de inteligência e agudeza, que alternavam com outras por meio das quais se comprovava estar em dia com os últimos romances de Sartre, Camus ou Simone de Beauvoir, ou com traduções de Heidegger e ensaios de Merleau Ponty [...]. Natacha me ensinou a não ter medo da sociedade, dos grandes escritores, dos embaixadores e dos políticos. Me ajudou a desenvolver essa parte de minha personalidade silenciada e inculta. Realmente era uma delícia escutá-los e participar de suas conversações, convidá-los e tornar-se amigo desses [sobretudo, Octavio Paz, de quem se aproximaram em Paris] e de outros escritores e pensadores notáveis" (González Casanova, 1995, p. 11).

19. "José Miranda e Silvio Zavala me ensinaram como trabalhar em história das instituições, e Ramón Iglesia, em história das ideias" (González Casanova, 1995, p. 11).

20. Sobre seus textos de história das ideias, ver Perus (1995), Rabiela (1995), Bagú (1995) e Lira (2013).

21. No prefácio à primeira edição em espanhol (1953) do livro El Mediterráneo y el mundo mediterráneo en la época de Felipe II, na Fondo de Cultura Económica, Braudel incluiu Pablo González Casanova em 
espagnole à travers des donnés de l'historiografie française, título que permite entrever a guinada para a sociologia, reforçada pelo contato estabelecido com o sociólogo Georges Gurvitch. Ao retornar ao México, oscilou ainda em relação às duas frentes possíveis de atuação. Reintegrou-se ao Colégio do México e publicou alguns livros como historiador na década de 1950, nas principais editoras: em coautoria com José Miranda, Sátira anónima del siglo XVIII (Fondo de Cultura Económica, 1953); Una utopia de América (Colégio do México, 1953); La ideología norteamericana sobre inversiones extranjeras (Editora da Escola Nacional de Economia da Unam, 1955); La literatura perseguida en la crisis de la colonia (Colégio do México, 1958). Ao mesmo tempo retornou como pesquisador ao IIs e tornou-se professor da ENCPys.

Durante as décadas de 1940 e 1950 participou, também, dos círculos letrados da Cidade do México. Inicialmente se envolveu, em colaboração com seu irmão Henrique, em um empreendimento editorial, a Colección Lunes (1944-1947), que publicou 31 volumes de coletâneas de contos de escritores mexicanos (Alfonso Reyes, Mariano Azuela, Martín Luis Guzmán, Agustín Yáñez e José Vasconcelos, entre outros). Pouco depois, vinculou-se ao célebre suplemento literário "México en la Cultura”, do jornal Novedades (1949-1964), dirigido por José García Terrés e por Fernando Benítez (Careaga, 1971; Camposeco, 2015). Também na década de 1950 fez parte do grupo - formado por Carlos Fuentes, Octavio Paz, Jaime García Terrés, Ramón Xirau, Emmanuel Carballo, Alí Chumacero, José Luis Martínez, Joaquín Díez-Canedo, Ernesto Mejía Sánchez y Víctor Flores Olea, entre outros (Garciadiego, 2014, p. 19) - que frequentava a Capilla Alfonsina, a casa de Alfonso Reyes ${ }^{22}$.

Vale a pena ainda mencionar outra possibilidade, que certamente o mobilizava no retorno da França ao México, a de ingressar na arena política, tal como ele mesmo admitiria anos mais tarde: "ao regressar ao México já estava pronto para integrar a classe política” (González Casanova, 1995, p. 12). A expectativa contida na frase, ainda que referida a quem a proferiu, é, também, expressiva do já mencionado alto grau de integração das elites intelectual e política, em função de uma experiência social e educacional compartilhada (ENP/Unam), condição necessária para se almejar uma posição no sistema político e que persistiria no México até pelo menos o final dos anos de 1980 (Camp, 1988; Zaid, 1998²3).

seus agradecimentos, mencionando "mis jóvenes alumnos don Pablo González Casanova y don Ernesto de la Torre Villar".

22. Sobre sua relação com o escritor Alfonso Reyes, vale a pena citar a seguinte evocação: "na formação de meus sentimentos intelectuais influíram muito mais os professores espanhóis e fora da academia Don Alfonso Reyes que, durante anos, convidou-me para jantar com ele e com Doña Manuelita, sua mulher, um sábado sim e outro não" (Casanova apud García, 2003).

23. Vale citar: "Em 1987, segundo o Dicionário biográfico, dos 1.156 funcionários mais altos do poder executivo, $98 \%$ tinha estudos superiores (mais da metade na Unam) e 48\%, pós-graduados; $70 \%$ tinha 
Esse itinerário plural desembocou, não obstante, na opção definitiva pela carreira acadêmica (como "herança" paterna, segundo diversos depoimentos) e pela sociologia, ao assumir o cargo de diretor da Escola Nacional de Ciências Políticas e Sociais, que exerceu entre 1957 e 1965, desempenhando ali um papel modernizador e mais empenhado na pesquisa sistemática (Reyna, 1979 e 2007; Castañeda, 1990; Arguedas e Loyo, 1979). Justamente nesse período, Pablo González Casanova concluiu (1963) e publicou (1965) seu livro principal, A democracia no México, pela Ediciones Era, que, juntamente com Siglo Xxi e Joaquín Mortiz (Anderson, 1996), todas editoras privadas, surgiram como alternativa na década de 1960 ao monopólio exercido até então pela Fondo de Cultura Económica, que havia recusado a publicação do trabalho (Arciniegas, 1994; Rosenmann, 2008). Nascido como um clássico das ciências sociais mexicanas, sua primeira edição de 3 mil exemplares esgotou-se em oito meses. Nos dez anos seguintes o livro teve mais seis edições $(1967,1969$, 1971, 1972, 1974 e 1975) e foi traduzido em quatro línguas. Em 1967, ao português, no Brasil (Civilização Brasileira); em 1969, ao francês (Anthropos); em 1970 ao inglês (Oxford, Nova York) e ao alemão (Munster). A versão norte-americana foi prefaciada elogiosamente pelo importante sociólogo norte-americano Irving Louis Horowitz.

O início da década de 1960 sinalizou o estremecimento da legitimidade do sistema político mexicano, lastreado no presidencialismo de partido único, o PRI, e o início de reivindicações pela democratização. Na base desse processo, contido até o final da década pelo ciclo econômico ainda favorável, estariam os processos de industrialização, urbanização, crescimento populacional, especialmente dos setores populares e médios urbanos. Além disso, como resultante das políticas educacionais e culturais encampadas pelo Estado pós-revolucionário, havia ocorrido uma expansão progressiva do sistema educacional nos três níveis, o aumento do público leitor (recrutado nos novos grupos sociais emergentes), o adensamento e a diferenciação do campo cultural e de suas linhas de força ${ }^{24}$.

experiência acadêmica (docência e pesquisa), $60 \%$ pertencia a academias e organismos semelhantes, $30 \%$ havia publicado livros; só $4 \%$ havia alcançado cargos públicos eleitoralmente; nenhum estava filiado a partidos de oposição; a metade havia nascido na capital e predominavam membros das classes altas. Desde então, a universidade se converte em apêndice do Estado" (Zaid, 1998, p. 28).

24. Certamente, um uso ao pé da letra do conceito de campo - e do esquema teórico de Bourdieu, aplicado, exemplarmente, em As regras da arte (1996) - inviabiliza sua aplicação direta aos casos latino-americanos, uma vez que sua construção teve como referência a experiência francesa. Acreditamos, entretanto, que os ganhos interpretativos derivados de sua utilização justificam uma certa flexibilização do conceito, que se faz necessária para abarcar os contextos das sociedades latino-americanas. Em tal direção, a rigor, deveríamos falar antes de campos em constituição e não em campos já plenamente formados e autonomizados. 
Nesse processo, a Unam, que se expandira sensivelmente ${ }^{25}$, foi decisiva como locus de um conjunto de iniciativas que a ela se associavam em maior ou menor grau. Os periódicos Revista de la Universidad de México, Revista Mexicana de Literatura, os suplementos literários "México en la Cultura” (1949-1961) do jornal Novedades e "La Cultura en México" da revista Siempre! canalizaram o descontentamento cada vez mais abrangente com o nacionalismo cultural, que fora uma ideologia dominante desde a década de 1920, aproximadamente. Associou-se a esse contexto o surgimento, já mencionado, no setor privado, das editoras Era (1960), Joaquín Mortíz (1962) e Siglo xxi (1965). A democracia no México deu forma a essas tensões e reposicionou favoravelmente a sociologia mexicana na tábua de valores do sistema acadêmico de então ao eleger como objeto e submeter à crítica um tema que até então era tabu no debate intelectual: a natureza do sistema político pós-revolucionário. A questão fora tratada por analistas estadunidenses, como Ernest Gruening, Frank Tannenbaum, e havia ao menos dois antecedentes entre os intelectuais do país, Jesús Silva Herzog (1943) e Daniel Cosio Villegas (1947), nos textos que publicaram em Cuadernos Americanos, mas ninguém a havia enfrentado de forma sistemática (Meyer, 2005; Lémperière, 1992).

A conjugação entre rigor científico (garantido pela articulação entre teoria e pesquisa empírica) e análise política que caracteriza sua argumentação garantiu à Democracia no México uma recepção muito favorável e ampliada, reforçada pelo acirramento progressivo das tensões políticas nas décadas de 1960 e 1970 . De qualquer modo, rever os diagnósticos formulados no livro permite problematizar as modalidades de relação entre os campos político e acadêmico no México pós-revolucionário, que teriam condicionado tais diagnósticos.

Logo no início do livro a contraposição entre "modelo" (europeu/norte-americano) e "realidade" (González Casanova, 1965, p. 11) permite ao autor problematizar a experiência democrática mexicana pós-revolucionária, caracterizada em linhas gerais pela ausência de sistema partidário; submissão do sindicalismo ao poder Executivo, do Legislativo ao Executivo, dos governos estaduais ao governo central. Deslocadas ou submetidas as antigas bases do poder político - caudilhismo, exército, igreja -, o presidencialismo seria fortalecido, ainda que acossado pelas demandas do empresariado moderno emergente. A dominação exercida sobre o México pelos Estados Unidos, sobretudo no terreno econômico, mas também político e cultural, constituiria uma ameaça à soberania do Estado, embora González Casanova sublinhasse a existência de "sentimento antiamericano" generalizado (González

25. Entre 1944 e 1966, o número de matriculas na Unam subiu de 22 mil a 79 mil (Domínguez Martínez, 2010). 
Casanova, 1965, p. 55). Apesar desses obstáculos, o Estado pós-revolucionário teria cumprido funções importantes ao garantir a estabilidade política e o desenvolvimento econômico de modo mais eficiente que outros países latino-americanos (González Casanova, 1965, p. 60).

Não obstante, o exame detido das relações entre "estrutura social e estrutura política" (González Casanova, 1965, p. 61) apontaria falhas que deveriam ser corrigidas. A sobrevivência de um setor excluído da sociedade, sobretudo a população indígena, submetido ao que o sociólogo denominava "colonialismo interno", a dominação do setor tradicional pelo setor moderno, seria o calcanhar de Aquiles mexicano. A marginalização social seria também política, e a integração dos excluídos constituiria uma necessidade inadiável. Nessa direção, a democratização seria um passo decisivo. Mas o que significava esse processo para o autor? Vejamos uma passagem decisiva:

O fato de que no desenvolvimento europeu e norte-americano o motor para o estabelecimento do mercado interno tenha sido um sistema de partidos e sindicatos próximos ao modelo clássico e que no México o desenvolvimento até agora alcançado se deva a um sistema sui generis de governo nos obriga a pensar que a democratização do país no interior do regime capitalista exige uma imaginação política especial, uma verdadeira criação democrática, evitando imitar as formas de governo da democracia clássica, mas sem se deter, tampouco, nas formas para-democráticas que até agora nos tem sido relativamente úteis como nação: a transformação não exige necessariamente chegar a um regime parlamentarista, que, aliás, se encontra em decadência e já não corresponde às expectativas da política neocapitalista; a transformação exige idealizar formas democráticas dentro do partido governamental, instituições parlamentares que controlem obrigatoriamente o poder econômico do setor público, instituições representativas para a descolonização nacional, instituições que favoreçam a manifestação de ideias dos grupos minoritários políticos e culturais, incluídos os grupos indígenas; instituições que fomentem os periódicos nos partidos e a representação indígena, instituições que fomentem a democracia sindical interna e as formas autênticas de conciliação e arbitragem, ou seja, formas de governo novas que aproveitem a experiência nacional e a levem adiante em um ato de criação política, cuja responsabilidade fica nas mãos da própria classe governante e, sobretudo, dos grupos políticos e ideológicos mais representativos da situação nacional. (Casanova, 1965, pp. 123-124, grifos nossos).

Salvo engano, Pablo González Casanova não recusou o sistema político resultante da Revolução Mexicana e seu partido único de sustentação, o PRI, mas sugeriu, fundamentalmente, a democratização de seus mecanismos de recrutamento interno. Aperfeiçoado o sistema político, mas não como cópia dos modelos estrangeiros, haveria a possibilidade de alcançar o desenvolvimento efetivo do país e lograr a integração 
social e política de sua população marginal. Joseph Kahl acertou, portanto, ao sugerir que, ao menos em $A$ democracia no México, o autor estaria "dentro da revolução" (Kahl, 1986, p. 147). Do nosso ponto de vista, isso significa que a substância e o alcance de sua crítica ao sistema político mexicano deveriam ser compreendidos em função das relações então vigentes de dependência do campo acadêmico ao político, que implicava um grau restrito de autonomia aos intelectuais, especificamente aos sociólogos que podiam enunciar críticas, porém contidas, aos desajustes do sistema, como se encarnassem o papel de ombudsman do governo.

Havia, entretanto, graus de compromisso e distanciamento variáveis segundo as disciplinas praticadas, posicionando-se o direito e a economia no polo mais dependente do Estado e as ciências humanas e sociais no polo menos dependente. No interior deste último, os sociólogos detiveram, progressivamente, maior autonomia, sobretudo a partir de sua profissionalização mais consistente desde a segunda metade da década de 1950. Seu distanciamento estrutural em relação ao polo do poder implicaria, em contrapartida, maior liberdade de expressão. Assim mesmo, conforme sugerimos anteriormente, Pablo González Casanova, quem mais avançou nessa direção, em $A$ democracia no México, formulou uma interpretação distanciada apenas parcialmente dos pressupostos que legitimaram o sistema político desde a institucionalização da revolução no final da década de 1920. Apesar de constatada, a centralidade do PRI nesse sistema não foi diretamente combatida no livro em questão.

Após a publicação de $A$ democracia no México, González Casanova deixou a direção da ENCPys e assumiu o IIs (1966-1970) ${ }^{26}$, justamente em um período de extrema polarização política, no qual as tensões entre o governo de Díaz Ordaz (1964-1970) e os estudantes universitários desembocaram na repressão sangrenta de Tlatelolco, ocorrida em 1968. Durante o mandato presidencial seguinte, de Luis Echeverría (1970-1976), que era seu amigo e com quem havia estudado na Escola Nacional de Jurisprudência, o sociólogo alcançaria a posição política mais elevada de sua trajetória, com sua indicação ao cargo de reitor da Unam ${ }^{27}$ (abril de 1970/dezembro de 1972), do qual acabaria renunciando após novos conflitos com os estudantes (Torres Guillén, 2014).

26. Sobre esse período, ver Farfán (1994). Ainda na década de 1960, publicou os livros Las categorias del desarollo económico y la investigación en ciencias sociales (1967) e Sociología de la explotación (1969), que aprofundam problemas teóricos derivados de $A$ democracia no México. Segundo o texto citado, esse conjunto de trabalhos pode ser entendido como o núcleo de um programa de pesquisa formulado por González Casanova.

27. A reitoria da Unam tem no México um peso político muito grande, equiparável ao de um ministro de Estado. 
Em função dos parâmetros mencionados na introdução deste texto - transformações sociais e dinâmicas de urbanização, relações entre intelectuais e política, modalidades de organização dos sistemas acadêmicos, padrões de recrutamento social dos cientistas sociais, obras produzidas -, ensaiaremos agora uma comparação entre as experiências iniciais de institucionalização da sociologia (1930-1970) no México, na Argentina e no Brasil ${ }^{28}$, centrada nas trajetórias dos personagens identificados pela literatura especializada como as lideranças principais da modernização dessa disciplina nos três países: Pablo González Casanova, Gino Germani e Florestan Fernandes.

Nos três casos, a sociologia foi implantada institucionalmente em grandes cidades em processo de metropolização, às voltas com transformações de peso na sociedade, na economia, na política e na cultura. Mas há diferenças importantes a serem notadas, em função de nosso argumento. A principal delas refere-se ao peso da imigração europeia ocorrida em larga escala entre o último quarto do século XIX e as três primeiras décadas do século XX em Buenos Aires e em São Paulo, que promoveu nessas cidades a constituição remota (mais acelerada em Buenos Aires) de uma nova classe média urbana diretamente interessada e envolvida no sistema de educação superior criado pelas elites nativas e nas possibilidades de ascensão social por meio da profissionalização das novas disciplinas acadêmicas, como foi o caso da sociologia (Jackson e Blanco, 2014). Na Cidade do México, não houve imigração maciça, e a formação das classes médias urbanas, embora também importante, foi mais lenta e conturbada, graças ao processo revolucionário e suas consequências (Iturriaga, 1951; Loaeza, 1988). Esse quadro ajuda a compreender por que em Buenos Aires e em São Paulo prevaleceu, na metade do século Xx, para os cursos de ciências sociais na UBA (Germani, 1956; Germani e Sautu, 1965) e na UsP (Miceli, 1989), o recrutamento mesocrático de estudantes, enquanto na Cidade do México a origem social dos estudantes da ENCPys/Unam concentrou-se ainda nas elites (Benítez Zenteno, 1961).

Outra diferença diz respeito ao fato de São Paulo nunca ter sido capital política do Brasil, enquanto Buenos Aires e a Cidade do México o serem desde a independência da Argentina e do México, o que implicou nestas duas últimas um alto grau de politização da vida intelectual, que nunca se deu em São Paulo do mesmo modo

28. Para uma comparação mais abrangente, ver o livro As ciências sociais na América Latina em perspectiva comparada (2006), organizado por Hélgio Trindade, especialmente o capítulo final "Ciências sociais na América Latina em perspectiva comparada: Argentina, Brasil, Chile, México e Uruguai” (Trindade, Garretón, Murmis, Reyna e Sierra), no qual nos apoiamos parcialmente. 
(no Rio de Janeiro, sim). Nos contextos que nos interessam, isso explicaria o grau menor de politização da USP, desde sua criação em 1934, enquanto a UBA e a Unam foram sempre extremamente politizadas (cada uma à sua maneira, como veremos). Tal diferença teve efeitos diretos nos padrões de institucionalização das ciências sociais e nas orientações temáticas das pesquisas estabelecidos em cada caso. Nessa direção, vale lembrar que Florestan Fernandes, como veremos a seguir, enfrentou temas diretamente ligados à política apenas na década de 1960 e que, mesmo assim, seus trabalhos não abordaram o Estado ou as instituições políticas propriamente $\operatorname{ditas}^{29}$. Em oposição, os trabalhos principais de Germani, sobre as bases sociais do peronismo, e de González Casanova, sobre os impasses da democracia mexicana, enfrentaram tais problemas diretamente, estabelecendo as bases de uma sociologia política propriamente dita.

Tais cidades constituíram-se desde o início do século xx como "metrópoles culturais" ${ }^{\prime 30}$. Como locus dos empreendimentos culturais e científicos, deve-se notar o alto grau de centralização (tomando os países como referência) em Buenos Aires e na Cidade do México. São Paulo nunca monopolizou tais empreendimentos, divididos (ou disputados) com o Rio de Janeiro e, em menor grau, com Recife, Salvador, Belo Horizonte, Porto Alegre etc. Quanto às estruturas dos mercados de bens culturais (imprensa, editoras, revistas, museus, teatros) estabelecidos nessas cidades, eles foram: predominantemente privado em Buenos Aires, predominantemente público na Cidade do México e misto em São Paulo.

As experiências transcorridas nos três países são muito significativas para se pensar o jogo complexo que relaciona o campo intelectual e o campo político - especialmente o conjunto de relações que envolvem os cientistas sociais nessa interface. Como se relacionam tais instâncias? Em primeiro lugar, por meio das políticas educacionais encampadas pelos governos nacionais e estaduais, sobretudo as que se referem ao ensino superior. Desse ponto de vista, o Estado foi um promotor direto da vida intelectual, envolvido na produção das condições de sua autonomização, uma vez que a universidade pública impulsionou esse processo, principalmente na dimensão mais específica que nos interessa. A Argentina foi favorecida desde o final do século XIX por políticas democratizantes, tanto na base como no topo do sistema educacional, e no começo do século xx já havia diversas universidades espalhadas pelo país. Esse conjunto configurava um sistema universitário público e nacional, apesar de centralizado em Buenos Aires, o que no Brasil ocorreria apenas durante

29. Devemos matizar essa afirmação, entretanto, uma vez que os principais discípulos de Florestan Fernandes, Fernando Henrique Cardoso e Octávio Ianni, escreveram trabalhos precursores sobre o papel do Estado e dos atores políticos no desenvolvimento econômico.

30. Sobre São Paulo, ver Arruda (2015); Buenos Aires, Sarlo (2010); Cidade do México, Kandell (1990). 
a década de 1960 e pelas mãos da ditadura militar. As universidades públicas brasileiras, criadas nos anos de 1930, resultaram de iniciativas pontuais comprometidas com interesses políticos específicos e restringiram-se ao Estado de São Paulo e ao Distrito Federal, que na época era o Rio de Janeiro (Cardoso, 1982; Schwartzman, 1979; Cunha, 2007). No México, desde o final do porfiriato e, sobretudo, a partir da revolução, o Estado ampliou progressivamente, ao longo do século xx, o investimento na educação superior, concentrada até o final dos anos de 1960 na Cidade do México e na Unam, que evoluiu de uma pequena universidade nos anos de 1910 até uma grande universidade na década de 1960 e seguintes (Kandell, 1990; Lempérière, 1992; Schulte, 2010).

Em segundo lugar, no Brasil e no México, principalmente, o Estado constituiu-se como um empregador direto dos intelectuais, incorporando-os em cargos políticos, técnicos ou burocráticos. No caso brasileiro, durante o Estado Novo, com a centralização do poder político, esse processo alcançou dimensões extremadas, servindo diretamente à sustentação do regime e, ao mesmo tempo, remediando a fragilidade do mercado cultural então existente (Miceli, 2001). Tais mecanismos de cooptação foram mais frequentes, ainda, no caso mexicano, no Estado pós-revolucionário. A partir de meados dos anos de 1940, a fração dominante da elite política mexicana seria recrutada entre graduados da Unam (Camp, 1986). Na Argentina, durante a República Oligárquica (1880-1916), os intelectuais ocuparam postos burocráticos e orbitaram a esfera do poder, mas a cooptação dos intelectuais pelo Estado seria interrompida desde a democratização do sistema político, demarcada pela eleição de Yrigoyen em 1916 (Halperin Donghi, 2000). A partir de então, a relação dos intelectuais com o Estado caracterizar-se-ia por um maior distanciamento, e mesmo oposição, como ocorrido emblematicamente no curso do peronismo (Sigal, 1991).

Outra modalidade de fricção entre os campos político e acadêmico/intelectual refere-se às intervenções diretas do Estado nas universidades (repressão, censura, demissão de professores), mais frequentes em conjunturas de autoritarismo político. De acordo com esse parâmetro, os casos brasileiro e mexicano foram menos acidentados (apesar de episódios gravíssimos como o massacre dos estudantes em Tlatelolco, no ano de 1968) que o argentino; este último mais profunda e diretamente afetado ao longo do século Xx por fraturas decorrentes de episódios de repressão política.

As relações entre os campos político e intelectual, entretanto, não se restringem ao comportamento do Estado em relação à universidade e aos intelectuais, envolvendo, também, os sentidos atribuídos por estes últimos à sua atividade, polarizada entre o empenho na sua dimensão específica e/ou na participação na vida pública. Nesse diapasão, e condicionados pela história política de cada país, os intelectuais adotaram linhas de comportamento mais ou menos empenhadas politicamente 
conforme as circunstâncias. Segundo Daniel Pécaut (1990), se tanto no Brasil como na Argentina a atividade dos intelectuais no século Xx teria sido orientada por diferentes "missões" políticas (nacionalismo, desenvolvimentismo etc.), na Argentina o fardo da política sobre os intelectuais seria ainda mais pesado. Assim, há quase um consenso na literatura (Sigal, 1991; Terán, 1991; Neiburg, 1998; Sarlo, 2001) a respeito da impossibilidade de se dissociar nesse país a vida intelectual e acadêmica no século $\mathrm{xx}$ dos dinamismos próprios à história política nacional. Não se pode esquecer que a universidade se constituiu desde a reforma universitária de Córdoba em 1918 - que estabeleceu o princípio da autonomia universitária e do governo tripartido entre docentes, alunos e graduados - como um ator político muito importante da vida pública argentina, fonte tanto de sua visibilidade como de sua vulnerabilidade (sujeita a intervenções diretas dos poderes políticos). No México, desde a institucionalização do Estado revolucionário até a década de 1950, a maioria dos intelectuais mexicanos assumiu a ideologia nacionalista legitimadora desse sistema político, ou seja, direcionou sua atividade a favor do projeto revolucionário, apesar das dissensões ocorridas.

Voltemos agora ao problema enunciado na introdução. Como explicar a emergência de lideranças como Florestan Fernandes, Gino Germani, Pablo González Casanova? A resposta deve ser buscada nas transformações sociais já mencionadas e na modernização das organizações acadêmicas desses países no século xx. Florestan e Germani se estabeleceram como "chefes de escola" (Tiryakian, 1979; Bulmer, 1984), lideraram grupos de pesquisadores e dirigiram programas de pesquisa ambiciosos, entre as décadas de 1950 e 1960 (Jackson e Blanco, 2014); González Casanova desempenhou papel análogo no México.

A constituição anterior, na Argentina, de um sistema universitário no final do século XIX relativamente unificado e inclusivo, embora resultante de políticas conduzidas pelas elites dirigentes, impulsionou fortemente a rápida formação de um campo intelectual dinâmico, que teve na profissionalização da atividade acadêmica um de seus pilares mais importantes. Isso ocorreu de maneira pronunciada na Faculdade de Filosofia e Letras da UBA (1896), no interior da qual se fortaleceu uma cultura acadêmica que valorizava o ofício do professor universitário e a rotina do estudo sistemático. A sociologia foi introduzida nos cursos de filosofia e letras (e também nas faculdades de direito), e essa contingência implicou um ritmo lento de institucionalização, derivado, também, da inexistência de especialistas na matéria, e o que se produziu por muitas décadas restringiu-se a comentários dos clássicos estrangeiros, que tomavam como modelo as disciplinas humanísticas que se haviam afirmado no sistema universitário, como a filosofia, a crítica literária e a história. Deparando-se com esse cenário, renovado pela criação do Instituto de Sociologia em 1940, o 
imigrante italiano Gino Germani, graduado em economia na Itália e em filosofia na Argentina, moveu-se com dificuldade até que o contexto pós-peronista (1955-1966) permitiu a criação do curso de graduação em sociologia, que o teve como mentor e artífice. A dificuldade de entender sua obra e o programa que dirigiu a partir de então reside justamente em tal estrutura de possibilidades. Ele não teve mestres em sua matéria e foi obrigado a transpor a extrema politização da universidade argentina, para forjar e defender seu projeto, que reivindicava a sociologia como ciência. Foi, em sua disciplina, um autodidata. Evidentemente, não se teria tornado um "chefe de escola" fora da universidade, mas ele foi, como outros personagens destacados da vida cultural e científica argentina, alguém que se apoiou nas condições mais amplas que caracterizavam o tecido intelectual e artístico da cidade de Buenos Aires e, também, na densidade e na diversidade de seu mercado de bens culturais, instâncias que permitiram a ele ascender socialmente e ganhar legitimidade intelectual em meio às tensões políticas que marcaram o país desde os anos de 1930 e, sobretudo, depois da ascensão de Perón ao poder, em 1946. A politização infundiu-se em sua obra, toda ela associada aos "temas quentes" da conjuntura política - imigração e peronismo, sobretudo -, elhe permitiu praticamente monopolizar poderes acadêmicos e recursos institucionais no âmbito de sua disciplina, depois de 1955. A radicalização da política que levaria ao golpe de 1966 o afastou progressivamente da universidade e bloqueou por fim a continuidade de seu projeto acadêmico.

Embora haja controvérsia sobre a origem da sociologia brasileira, sua inserção institucional no ensino superior em cursos de graduação em ciências sociais ocorreu na década de 1930 com a criação da Escola Livre de Sociologia e Política - ELSP (1933), da Faculdade de Filosofia Ciências e Letras - FFCL-UsP (1934) e da Universidade do Distrito Federal - UDF (1935). As duas últimas eram universidades novas, mas vale lembrar que faziam parte de um sistema educacional acanhado, restritivo, e que não estavam integradas nacionalmente, o que só viria a se consumar na década de 1960. Os três cursos foram importantes, contudo o que logrou maior legitimação foi o da USP. Vejamos algumas de suas características principais. Apesar de recrutar poucos alunos por ano, oriundos de grupos sociais antes excluídos do ensino superior, como filhos de imigrantes e mulheres, a formação oferecida esteve a cargo de uma missão estrangeira oficial, de franceses, principalmente, que formataram o curso nos moldes da tradição durkheimiana. Se levarmos em conta que na ELSP militaram professores norte-americanos e alemães, constatamos a excepcionalidade dessa experiência e dos resultados extremamente frutíferos que dela derivaram. $\mathrm{O}$ alunato treinado pelos professores estrangeiros (o que também ocorreu no Rio de Janeiro, embora não com o mesmo peso) adquiriu disposições científicas e absorveu diretamente a bibliografia especializada europeia e norte-americana. Recebeu, portanto, formação sistemática, 
que constituiria um traço geracional. Nesse microcosmo, Florestan Fernandes se tornou sociólogo por inteiro valendo-se da experiência compartilhada com seus colegas, apesar de sua origem desfavorável que, de certa forma, se converteu em um trunfo para ele à medida que se destacava como o representante mais promissor de sua geração. Situado em uma universidade relativamente blindada das ingerências políticas, voltou-se inicialmente a "temas frios", como o folclore e a etnologia, que lhe permitiram granjear a reputação de pesquisador competente e reivindicar a sociologia como ciência. Desde que assumiu interinamente a chefia da Cátedra de Sociologia I em 1954, empenhou-se na constituição e na liderança de um grupo de pesquisadores e dirigiu programas de pesquisa centrados na questão racial e no problema do desenvolvimento econômico, "temas quentes” sintonizados com o contexto do pós-guerra e com o acirramento político que levaria ao golpe de 1964. Em seguida a esse evento, assumiu uma postura militante, em oposição ao governo militar, em função da qual seria aposentado compulsoriamente em 1969.

No México, criada no final do porfiriato (1910), a universidade foi, como vimos, progressivamente ajustada aos propósitos do Estado pós-revolucionário, ao mesmo tempo que as reivindicações por autonomia pela comunidade acadêmica promoveram o processo de profissionalização nas diversas especialidades constituídas. As primeiras gerações de professores universitários nas áreas de ciências sociais circularam entre cargos no poder público e postos na universidade, e isso dificultou o surgimento de 'intelectuais acadêmicos" (Coser, 1968) propriamente ditos. O Colégio do México, comparativamente, dispôs de maior autonomia para as atividades de pesquisa, beneficiado pela presença dos exilados espanhóis e pelas iniciativas modernizadoras do historiador mexicano Daniel Cosio Villegas. O desenvolvimento da sociologia (de maneira similar ao que se deu na Argentina) teve como lastros o ensino nos cursos de direito e as atividades de pesquisa no IIs (1930), instituto que prosperou desde que Lucio Mendieta y Nuñez assumiu sua direção em 1939, criando imediatamente a Revista Mexicana de Sociologia. Oriundo de família tradicional declinante e dispondo de capital social e cultural considerável, Pablo González Casanova se moveu do direito à história e desta à sociologia. No Colégio do México, obteve formação intelectual privilegiada, graças ao contato direto com os professores estrangeiros - como aconteceu a Florestan, mas não a Germani-, dos quais absorveu, também, padrões de trabalho sistemático. Concomitantemente, atuou como pesquisador no IIs, sob a orientação de Mendieta y Núñez. No final da década de 1940, à diferença de Florestan e Germani, que não fizeram pós-graduação no exterior, partiu para a França, onde obteve o título de doutor. Por algum tempo indefinido entre a história e a sociologia, seus primeiros trabalhos, como vimos, concentraram-se em história das ideias do período colonial. Lentamente, caminhou 
para a sociologia, movimento que se completou ao assumir, em 1957, o cargo de diretor da Escola Nacional de Ciências Políticas e Sociais (1951). Depois de um livro de pouca repercussão, Estudios de la técnica social (1958), no qual se alinhou (embora sem a mesma força retórica) a Gino Germani e Florestan Fernandes no intuito de estabelecer a sociologia como ciência empírica, sua aposta certeira se deu com A democracia no México (1965), que lhe garantiu amplo reconhecimento por submeter à interrogação sociológica, pela primeira vez, o sistema político de seu país. Como Florestan Fernandes, portanto, González Casanova transitou dos "temas frios" (história das ideias) aos "temas quentes" (sistema político), mas por razões distintas. A escolha dos "temas frios” por Florestan foi condicionada pelas tradições científicas que prevaleciam nas instituições em que se formou (ELSP e FFCL-USP), marcadas pela presença de professores franceses e norte-americanos, distanciados da política local por sua condição de estrangeiros. Se o mesmo argumento vale para González Casanova, por conta da presença dos espanhóis no Colégio do México, a escolha dos "temas frios" no começo de sua carreira foi condicionada, sobretudo, pela existência de uma censura velada, mas extremamente eficiente, à discussão pública do sistema político, que afetou, também, sua interpretação sobre os impasses da democratização no México.

\section{Referências Bibliográficas}

Anderson, Danny J. (1996), "Creating cultural prestige. Editorial Joaquín Mortiz". Latin American Research Review, 2 (31): 3-41.

Arguedas, Ledda \& Loyo, Aurora. (1979), "La institucionalización de la sociología en México". In: Arguedas, Ledda (org.). Sociología y Ciencia politica en México (un balance de veinticinco años). Cidade do México, Universidad Nacional Autónoma de México (Unam).

Arruda, Maria Arminda do Nascimento. (1995), "A Sociologia no Brasil: Florestan Fernandes e a 'escola paulista'". In: Miceli, Sergio (org.). História das Ciências Sociais no Brasil. São Paulo, Sumaré/Idesp/Fapesp, vol. 2.

(2015), Metrópole e cultura: São Paulo no meio século Xx. 2. ed. São Paulo, Edusp.

Bagú, Sergio. (1995), "El sentido de lo histórico en la obra de Pablo González Casanova”. Anthropos, 168: 59-63.

BIDON, Claude. (1983), Siglo XXI et son fondateur: une expérience originale d'édition. Perpignan, tese de doutorado, Institute d'Études Mexicaines, Université de Perpignan.

Blanco, Alejandro. (2009), "Karl Mannheim en la formación de la sociología moderna en América latina”. Estudios Sociológicos, 80 (xxviI): 393-431. . (2004), “Max Weber na sociologia argentina (1930-1950)”. Dados, 4 (47): 669-701. 
(2010), “José Medina Echavarría y el proyecto de una sociología científica”. In: PEREYRA, Diego (org.). El desarrollo de las ciencias sociales: tradiciones, actores e instituciones en Argentina, Chile, México y América Central. San José de Costa Rica, Flacso.

Braudel, Fernand. (1953), El Mediterraneo y el mundo mediterraneo en la época de Felipe II. Trad. Mario Monteforte Toledo e Wenceslao Roces. Cidade do México, Fondo de Cultura Económica.

Bulmer, Martin. (1984), The Chicago School of Sociology. Chicago, University of Chicago Press.

CAMP, Roderic. (1981), La formación de un gobernante: la socialización de los líderes politicos en el México post-revolucionario. Cidade do México, Fondo de Cultura Económica.

(1983), Los lideres politicos de México. Su educación y reclutamiento. Cidade do México, Fondo de Cultura Económica.

. (1988), Los intelectuales y el Estado en el México del siglo XX. Cidade do México, Fondo de Cultura Económica.

Camposeco, Victor Manuel. (2015), México en la cultura (1949-1961). Cidade do México, Conaculta.

Casanova, Pablo González. (1965), La democracia en México. Cidade do México, Ediciones Era. (1995), “Autopercepción intelectual de un proceso histórico”. Anthropos, 168: 7-21.

Castañeda, Fernando. (1990), “La constitución de la sociología en México”. In: Bolio, Francisco José Paoli (org.). Desarrollo y organización de las ciencias sociales en México. Cidade do México, Unam.

Colmenero, Sergio. (2003), Facultad de Ciencias Politicas y Sociales. Cidade do México, Facultad de Ciencias Políticas y Sociales.

Cosio villegas, Daniel. (1976), Memorias. Cidade do México, Joaquín Mortiz.

Díaz Arciniegas, Víctor. (1994), Historia de la casa Fondo de Cultura Económica, 1934-1996. Cidade do México, Fondo de Cultura Económica.

Dominguez Martinez, Raúl. (2010), “Historia de la Unam, 1945-1970”. In: Marsiske SCHulte, Renate (org.). La Universidad de México: un recorrido histórico de la época colonial al presente. Cidade do México, Unam.

Farfán, Rafael H. (1994), “La contribución de Pablo González Casanova a la formación de una teoría crítica de la sociedad en México (1966-1970)”. Sociológica, 24 (9): 51-89.

Garcia, Sylvia. (2002), Destino impar. São Paulo, Editora 34.

GarcíA, Alberto S. (2003), El pensamiento latinoamericano del siglo XX ante la condición humana. Cidade do México, Unam.

Garciadiego, Javier. (1996), Rudos contra cientificos: la Universidad Nacional durante la Revolución mexicana. Cidade do México, Colegio de México. (2010), “Los intelectuales y la Revolución Mexicana”. In: Altamirano, Carlos (org.), Historia de los intelectuales en América Latina. Buenos Aires, Katz, vol. 2.

Gurrieri, Adolfo (org.). (1980), La obra de José Medina Echavarría. Madri, Cultura Hispánica. 
Germani, Ana. (2004), Del antifascismo a la sociología. Buenos Aires, Taurus.

Germani, Gino. (1956), "Informe preliminar del Instituto de Sociología sobre las encuestas entre estudiantes universitarios”. Centro, 12: 34-46.

\& SAUTU, Ruth. (1965), "Regularidad y origen social de los estudiantes universitarios”. Buenos Aires, Instituto de Sociología, Facultad de Filosofía y Letras, Universidade de Buenos Aires.

Halperin Donghi, Tulio. (2000), "Intelectuales en la primera democracia argentina (19101930)”. In: Plotkin, Mariano \& González Leandri, Ricardo (orgs.). Localismo y globalización: aportes para una historia de los intelectuales en Iberoamérica. Madri, Consejo Superior de Investigaciones Científicas, Instituto de Historia.

Hennessy, Alistair. (1991), “The muralists and the revolution”. In: Camp, Roderic; Hale, Charles \& Zoraida, Josefina (orgs.). Los intelectuales y el poder en México. Cidade do México, Colégio do México.

ITURRIAGA, José. (1951), La estructura social y cultural de México: sociología, economía y politica nacional. Cidade do México, Fondo de Cultura Económica.

JACKSON, L. C. \& BLANCO, Alejandro. (2014), Sociologia no espelho: ensaistas, cientistas sociais e críticos literários no Brasil e na Argentina. São Paulo, Editora 34.

KaHL, Joseph. (1986), Tres sociólogos latinoamericanos: Germani, González Casanova y Cardoso. Cidade do México, Unam.

Kandell, Jonathan. (1990), La capital: la historia de la Ciudad de México. Buenos Aires, Javier Vergara Editor.

Kourí, Emilio. (2010), “Manuel Gamio y el indigenismo de la Revolución Mexicana”. In: Altamirano, Carlos (org.). Historia de los intelectuales en América Latina. Buenos Aires, Katz, vol 2.

Krauze, Enrique. (1976), Caudillos culturales en la Revolución mexicana. Cidade do México, Siglo XXI.

. (1980), Daniel Cosio Villegas: una biografia intelectual. Cidade do México, Joaquín Mortiz.

LEMPÉRIÈRE, Annick. (1992), Le clercs de la nation: intellectuels, État et société au Mexique. Paris, L'Harmattan.

Lida, Clara \& Matesanz, José Antonio. (1990), El Colegio de México: una hazaña cultural (1940-1962). Cidade do México, Colégio do México.

Lira, Andrés. (1986), “José Gaos y José Medina Echavarría, la vocación intelectual”. Estudios Sociológicos, 10 (IV): 11-27.

. (1989), “Autobiografía, humanismo y ciencia en la obra de José Medina Echavarría”.

Historia Mexicana, 153 (39): 329-347.

. (2013), "Prólogo". In: Casanova, Pablo González. Obras históricas, 1948-1958.

Cidade do México, Colégio do México. 
Loakza, Soledad, (1988), Clases mediasy politica en México. Cidade do México, Colégio do México. Mendieta Y Nuñez, Lucio. (1979), Tres ensayos sociológicos: Augusto Comte, Emilio Durkheim, Manuel Gamio. Cidade do México, Unam.

Meyer, Lorenzo (2005), “Agenda ciudadana: el espejo de Don Pablo”, Reforma, 15 dez.

Miceli, Sergio. (1989), “Condicionantes do desenvolvimento das ciências sociais”. In: (org.). História das ciências sociais no Brasil. São Paulo, Vértice/Idesp/Finep, vol. 1. (2012), Vanguardas em retrocesso. São Paulo, Companhia das Letras.

Monsiváis, Carlos. (1981), "Notas sobre la cultura mexicana en el siglo xx”. In: Villegas, Daniel Cosío (org.). Historia general de México. Cidade do México, Colégio do México, tomo 2. Morales Martín, Juan Jesús. (2012), José Medina Echavarria: vida y sociología. Madri, tese de doutorado, Universidad Complutense de Madrid.

Morcillo, Álvaro. (2008), "Historia de un fracaso: intermediarios, organizaciones y la institucionalización de Weber en México (1937-1957)”. Sociológica, 67 (23): 149-192.

Moya López, Laura. (2013), José Medina Echavarría y sociología como ciencia social concreta (1939-1980). Cidade do México, Colégio do México.

PÉCAut, Daniel. (1990), Intelectuais e a politica no Brasil: entre o povo e a nação. São Paulo, Ática. Perus, Francoise. (1995), "La obra primera de Pablo González Casanova”. Anthropos, 168: 26-41. Rabiela, Hira de Gortari. (1995), "Pablo González Casanova: una visión social y cultural del siglo XVIII novohispano”. Anthropos, 168: 53-58.

Ramírez, Víctor Erwin Nova. (2013), Arnaldo Orfila Reynal: el editor que marcó los cánones de la edición latinoamericana. Cidade do México, dissertação de mestrado, Universidad Autónoma Metropolitana, Unidad Azcapotzalco.

ResÉndiz SAUCEDo, Natanael. (2016), Los sabihondos impotentes: Estado, burocracia e intelectuales vistos desde la trayectória formativa de lucio Mendieta y Núnez (1911-1939). Cidade do México, tesis de maestria, Unam.

Reyna, José Luis. (1979), "La investigación sociológica en México". In: Arguedas, Ledda (org.). Sociología y ciencia politica en México: un balance de veinticinco años. Cidade do México, Unam.

. (2007), "A institucionalização das ciências sociais no México". In: TRINDAdE, Helgio (org.). As ciências sociais na América Latina em perspectiva comparada. Porto Alegre, Editora da UFRgS.

Roggiano, Alfredo. (1989), Pedro Henríquez Ureña en México. Cidade do México, Facultad de Filosofía y Letras de la Unam.

Rosenmann, Marcos Roitman. "Explotación, colonialismo y democracia en la obra de Pablo Gonzalez Casanova”. In: Medina, Verónica Carneiro \& CARreño, Alfredo Andrade (orgs.). Precursores de la sociología moderna en México. Cidade do México, Siglo XXI.

SARlo, Beatriz. (2010), Modernidade periférica: Buenos Aires, 1920 e 1930. São Paulo, Cosac Naify. 
Schulte, Renate Marsiske. (2010), "La Universidad Nacional de México (1910-1929)”. In: (org.). La Universidad de México: un recorrido histórico de la época colonial al presente. Cidade do México, Unam.

Serrano, Margarita Olvera. (1994), Lucio Mendieta y Núnéez y la institucionalización de la sociología en México, 1939-1965. Cidade do México, Universidad Autónoma Metropolitana.

Tiryakian, Edward. (1979), "The significance of schools in the development of sociology”. In: Snizek, William E.; Fuhrman, Ellsworth R. \& Miller, Michael K. Contemporary issues in theory and research: a metasociological perspective. Londres, Greenwood Press.

Torres Guillén, Jaime (2014), Dialéctica de la imaginación: Pablo González Casanova, una biografía intelectual. Cidade do México, La Jornada Ediciones.

Trindade, Hélgio (org.). (2006), As ciências sociais na América Latina em perspectiva comparada. Porto Alegre, UfRgs.

VÁrios autores. (1982), El exilio español en México, 1939-1982. Cidade do México, Fondo de Cultura Económica.

VÁRIOS autores. (1999), Los refugiados españoles y la cultura mexicana. Cidade do México, Colégio do México.

Zabludovski, Gina. (2002), "La emigración republicana española y el pensamiento alemán en México: la traducción de Economía y sociedad". Revista Mexicana de Ciencias Politicas y Sociales, 184 (45).

ZaID, Gabriel. (1998), De los libros al poder. Cidade do México, Océano de México.

Zenteno, Raúl Benítez. (1961), "El estudiante de la Escuela Nacional de Ciencias Políticas y Sociales". Revista Mexicana de Ciencias Politicas y Sociales, 23 (VII): 43-71. 


\section{Resumo}

O caudilho da sociologia mexicana: Pablo González Casanova e A democracia no México $\mathrm{O}$ artigo discute a trajetória do sociólogo mexicano Pablo González Casanova no interior do processo de institucionalização das ciências sociais no México, comparando-a com as de Gino Germani, na Argentina, e de Florestan Fernandes, no Brasil.

Palavras-chave: Sociologia; Institucionalização; Brasil; México; Argentina.

\section{Abstract}

The líder of Mexican sociology: Pablo González Casanova and The Democracy in Mexico

The article discusses the trajectory of the Mexican sociologist Pablo González Casanova within the process of institutionalization of the social sciences in Mexico, comparing it with those of Gino Germani in Argentina and Florestan Fernandes in Brazil. Keywords: Sociology; Institutionalization; Brazil; Mexico; Argentina.

Texto recebido em 29/2/2016 e aprovado em 29/2/2016. DoI: 10.11606/0103-2070. ts.2016.111597.

LUIZ CARLOS JACKSON é sociólogo e professor do Departamento de Sociologia da FFLCH-USP. E-mail:1jackson@usp.br.

ALEJANDRo BLANCO é sociólogo, professor da Universidade Nacional de Quilmes (UNQ), membro do Centro de Historia Intelectual da UnQ e pesquisador do Conicet.E-mail: ablanco@ unq.edu.ar. 


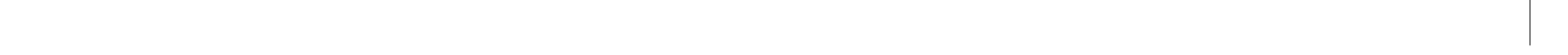

